\title{
Alimentação e escola: significados e implicações curriculares da merenda escolar*
}

\author{
José Arimatea Barros Bezerra
}

Universidade Federal do Ceará, Programa de Pós-Graduação em Educação

\section{Introdução}

Este estudo tem como foco principal a identificação das representações e práticas vinculadas à merenda escolar, buscando os significados dessa atividade não somente no espaço escolar como também no âmbito da realidade social em que se insere a escola, norteandose pelas seguintes questões: como a merenda escolar se manifesta no discurso e nas disposições práticas no contexto da escola pública de Ensino Fundamental? Que significados ela passa a ter nesse espaço? Quais suas implicações curriculares?

Para identificação das práticas concretas e do discurso sobre a merenda escolar, utilizei a teoria da ação social (Bourdieu, 1998) e a construção teórica das representações sociais (Moscovici, 1978). Em função da complexidade da temática na qual o objeto se insere, esse enfoque foi complementado por concepções de

* Elaborado com base nos resultados da tese de doutoramento em educação brasileira Comer na escola: significados e implicações, defendida junto ao Programa de Pós-Graduação em Educação da Universidade Federal do Ceará em 2002. comida e alimentação (DaMatta, 1997b) e a discussão de Sampaio (1999) sobre fome.

Parti do pressuposto de que não somente as representações sociais como as disposições práticas relacionadas à merenda escolar seriam geradas pelas predisposições duráveis (habitus) que os sujeitos da escola têm sobre essa atividade e sobre os alunos. Assim, são essas predisposições que orientam as formas de percepção desses sujeitos sobre a merenda escolar. E, considerando que o habitus é gerado também a partir da realidade concreta do ser social e dado que os alunos/pais (de alunos) e professores ocupam posições diferentes no espaço escolar e no meio social, pressupus que elaborassem representações diferentes sobre essa atividade.

Entendendo habitus como disposições duráveis, estruturas estruturadas e estruturantes (Bourdieu, 1998), tomei ainda como pressuposto que as predisposições dos professores sobre a merenda e o aluno - e as consequentes representações - poderiam conduzir e/ou modificar ações do cotidiano escolar, em particular as atividades curriculares, que foram consideradas a partir do enfoque da teoria crítica do 
currículo (Apple, 1999, 1995, 1989; Escolano, 1998; Moreira \& Silva, 1995).

A noção de habitus foi tomada, assim, com a finalidade de aproximação da compreensão mais ampla de representação social presente na teoria moscoviciana. Para essa teoria, representação social não é compreendida como sendo determinada apenas pelas condições objetivas, conforme o conceito de representação coletiva de Durkheim (apud Aron, 1993), mas também como estrutura estruturante, isto é, que pode afetar as condições concretas da sociedade, imprimindo-lhes a perspectiva subjetiva por meio da ação social. E na base das representações está o habitus, na perspectiva de Bourdieu.

Discutindo acerca dessa aproximação da noção de habitus em Bourdieu com o conceito de representação social em Moscovici, Domingos Sobrinho (1997, p. 30) afirma que a teoria moscoviciana das representações sociais "permite-nos compreender as ações humanas não somente como resultado de experiências acumuladas e de sistemas de disposições incorporadas mas também como produto da ação do indivíduo sobre si mesmo e sobre o mundo exterior”.

Na perspectiva de Moscovici (1978), a representação social não é algo passivo, apreendido nos moldes de uma fotografia. Trata-se de uma compreensão ativa, uma vez que ela modela o que é dado do exterior. A representação social reproduz, mas a partir do remanejamento de estruturas produz uma remodelação dos elementos anteriores. Traduzindo para o objeto em estudo, a representação promoveria uma reconstrução da merenda escolar no contexto dos valores e das noções (predisposições), das regras dos quais ela (representação) se torna solidária.

Segundo Moscovici (1978), representar não consiste somente em selecionar, completar um ser objetivamente determinado com um suplemento de origem subjetiva. É ir mais além, é elaborar uma doutrina que facilite a tarefa de decifrar, predizer ou antecipar os atos de quem representa. Assim, são duas as funções da representação social: a primeira consiste em vincular o objeto a um sistema de valores, noções e práticas que conferem aos indivíduos as formas de se orientar no meio social e material e de o denominar (objetivo prático); a segunda função visa propor aos membros de uma comunidade um instrumento de códigos para denominar e classificar de maneira clara as partes do seu mundo, de sua história individual ou coletiva.

O trabalho de representação consiste em atenuar estranhezas (provocadas por objeto ou noção nova), induzi-las no espaço comum, provocando o encontro de visões, de expressões separadas e díspares que num certo sentido se procuram. Esse trabalho de formação da representação ocorre através dos processos de ancoragem e objetivação.

O objeto de estudo se enquadra numa categoria que apresenta interfaces tanto com a existência física como com a construção social e a expressividade do ser humano. Merenda é alimento e comida. Carrega, assim, expressivo significado para o ser humano, ultrapassando a mera satisfação de necessidades biológicas. Segundo Zaluar (1985), alimentação é a categoria principal de articulação do pensamento dos pobres urbanos sobre sua condição. Além de poderoso símbolo de prestígio social e riqueza, emerge como uma categoria que estabelece fronteiras entre os pobres e os que não são pobres, bem como favorece a identidade social de classe.

Para Roberto DaMatta, a comida é um importante código de expressão da sociedade brasileira, tanto quanto a política, a economia, a família, o espaço e o tempo. Todavia, há diferenças entre comida e alimento. "Alimento é tudo que pode ser ingerido para manter a pessoa viva; comida é tudo que se come com prazer, de acordo com as regras de comunhão e comensalidade”. (DaMatta, 1997b, p. 55).

Discutir comida/alimentação implica considerar outra categoria inseparável do ato de comer, notadamente quando se trata da população mais pobre: a fome. Através do levantamento de dados inicial, pude compreender que a aproximação dos significados da merenda não poderia acontecer sem referência à problemática da fome, não somente pelo fato de a escola se localizar num espaço marcado pela pobreza, mas porque essa questão está presente no discurso dos sujeitos envolvidos na pesquisa. Para contemplar essa 
interface do objeto de estudo, tomo como suporte o estudo de Sampaio (1999), que discute a Geografia da fome no Ceará.

A partir desse enfoque teórico, o desenvolvimento da pesquisa aconteceu, de modo geral, em três etapas. A primeira consistiu no aprofundamento da revisão da literatura pertinente ao tema e dos estudos teóricos citados, inclusive sobre cotidiano (DaMatta, 1997a, Heller, 1992; Carvalho \& Paulo Netto, 1996). Com o aprofundamento da revisão de literatura pude mapear as discussões qualitativas sobre a temática no Brasil e compreender de forma mais clara o processo histórico de construção da merenda escolar. Essa etapa teve por objetivo a elaboração de um quadro conjuntural mais amplo da temática e o refinamento da base teórica da pesquisa, necessários à análise contextualizada dos dados coletados.

A segunda etapa foi pautada pelo levantamento de dados no contexto (cotidiano escolar e vivências da comunidade, sobretudo práticas alimentares) de uma escola de Ensino Fundamental pertencente à rede estadual de ensino localizada em um bairro de Fortaleza. Optei pelo enfoque no cotidiano escolar por acreditar que ele é fundamental quando se busca compreender ações, interações, rotinas e relações sociais que caracterizam uma determinada realidade e suas respectivas construções simbólicas e representacionais. Considerando o cotidiano como fonte de conhecimento e prática social (Heller, 1992; Carvalho \& Paulo Netto, 1996), sua observação (o antes, o durante e o depois dos rituais da merenda na organização escolar) constituiu-se como o instrumento privilegiado, tanto para coleta de dados como para confirmação e/ou entendimento de informações provenientes das entrevistas e dos questionários. Da observação sistemática do dia a dia da escola, ${ }^{2}$ procurei obter um quadro configurativo

${ }^{2}$ Minha presença na escola ocorreu entre os meses de fevereiro e novembro, sendo cinco meses no turno da manhã e cinco no da tarde, com frequência não inferior a quatro dias semanais, sem interrupção durante as férias de julho, pois nesse mês parte dos alunos permaneceu na escola, participando da colônia de férias, e a distribuição de merenda continuou, acrescentada de um almoço.
(André, 1989) detalhado do universo concreto e das formas simbólicas ${ }^{3}$ da merenda escolar.

Após o período de observação e quando me senti suficientemente familiarizado com o dia a dia da escola e mais próximo dos sujeitos desse espaço, iniciei as entrevistas abertas com duas integrantes do núcleo gestor (diretora administrativa e coordenadora comunitária), sete professoras (dos ciclos I e II, da aceleração II, de uma turma especial, composta de alunos com dificuldades de aprendizagem e as três merendeiras da escola. ${ }^{4} \mathrm{O}$ roteiro dessas entrevistas foi organizado buscando contemplar as questões básicas do estudo, complementado por aspectos que, durante a observação, foram considerados relevantes para a compreensão da problemática naquele espaço. Com essas entrevistas busquei identificar quais representações sociais sobre a merenda escolar eram elaboradas por esses profissionais, verificando a influência dessas representações sobre as práticas e disposições que orientariam os rituais da merenda e suas implicações para as atividades curriculares. A seleção dos professores foi feita a partir de dois critérios: que o professor atuasse nas séries iniciais (ciclo I e II, aceleração I e II) nos turnos da manhã e/ ou tarde e fosse voluntário. ${ }^{5}$ As atividades de coleta de dados junto aos alunos constaram da produção

\footnotetext{
${ }^{3}$ Formas simbólicas são aqui entendidas conforme Thompson
} (1990, p. 373): "produtos social e historicamente situados e estruturalmente articulados, através dos quais algo é dito ou representado”.

${ }^{4}$ Além das entrevistas, acompanhei as rotinas de trabalho das merendeiras, tendo oportunidade, por imposição da carência de pessoal, de ajudar por diversas vezes no manuseio de caldeirões ferventes do fogão para o chão e vice-versa. Essa convivência diária com elas na cozinha me permitiu ter acesso a informações privilegiadas sobre as relações implícitas que acontecem na escola e, principalmente, sobre a vida real da comunidade onde se localiza a escola.

${ }^{5}$ A escolha das professoras foi feita a partir de conversas informais, momento em que eu sondava o interesse da professora em colaborar com a pesquisa concedendo uma entrevista. No ato da entrevista, solicitava autorização para gravação da conversa e publicação de parte dela, mediante a garantia do anonimato da autoria. 
de desenhos e preenchimento de questionários, ${ }^{6}$ prérequisitos para a seleção dos dois grupos finais de alunos (com número de quatro a seis membros cada) que participariam de discussões focais sobre o tema, com o fim de explicitar suas representações sobre o comer na escola. ${ }^{7}$ Foram alunos de uma turma de ciclo II do turno da tarde, porque nesse nível teriam noções de leitura e escrita suficientes para responder aos questionários já referidos. Com tais instrumentos, reuni descrição de cenários, ações, interações, fatos, formas de linguagem e outras expressões articuladas que permitiram estruturar um quadro configurativo (André, 1989) da merenda no cotidiano da escola, que foi tomado como um dos referenciais de análise dos significados ${ }^{8}$ e representações do comer na escola.

${ }^{6}$ Foram aplicados questionários que procuravam identificar: opinião do aluno sobre a escola; informações pessoais do aluno; preferências e práticas alimentares pessoais e familiares (aplicados às segundas, quartas e sextas-feiras, durante quatro semanas). $\mathrm{A}$ busca de informações pessoais sobre o aluno teve por objetivo suprir a necessidade de saber quem eram os alunos, com quem viviam etc., uma vez que os dados registrados na ficha individual arquivada na secretaria da escola não contemplavam informações sobre aspectos essenciais para conduzir de forma mais eficaz as etapas seguintes de coleta de dados.

${ }^{7}$ Essa atividade não aconteceu conforme eu planejara porque a proposta de seleção de um grupo para a entrevista causou mal-estar entre as crianças, que prontamente demonstraram que se sentiriam discriminadas caso não fossem entrevistadas. Também a organização interna da turma, em pequenos grupos, cujos membros eram tão próximos entre si mas altamente excludentes com relação a pessoas de outros grupos, mostrava a inviabilidade de formar uma equipe mista de alunos para a entrevista. Logo, o número de alunos que participaria das entrevistas aumentou de oito para 25, pois tive que optar por entrevistar todos os alunos da turma. Essas conversas foram decisivas para a compreensão da relação entre a frequencia deles à escola e a merenda, explicitando como concebem o comer na escola e os motivos que os fazem procurar/frequentar essa instituição.

${ }^{8}$ As formas simbólicas "não são apenas concatenações de elementos e suas inter-relações; são também, tipicamente, representações ‘de algo’, apresentam ou retratam alguma coisa, dizem algo ‘sobre' alguma coisa”, afirma Thompson (1990, p. 189).
Em decorrência do enfoque teórico e da abordagem de cotidiano já esboçados, o levantamento de dados aconteceu, de forma complementar, no espaço do entorno da escola, envolvendo mães de alunos, proprietários de mercearias (bodegas)/mercadinhos e feirantes. Partindo do suposto de que as predisposições das pessoas envolvidas na pesquisa refletem sobremaneira seu meio social, ou seja, a realidade de fome/alimentação de sujeitos históricos e materialmente situados, percebi que a busca dos significados da merenda apenas no espaço da escola não daria conta de uma aproximação mais profícua da complexidade da problemática. Ademais, o resultado de uma comparação inicial dos dados coletados no interior da escola em levantamento exploratório mostrou divergências significativas entre as representações dos alunos sobre a merenda e aquelas elaboradas pelo grupo de sujeitos formado por professores, gestores e merendeiras. Nessa fase, utilizei como suporte teórico as discussões de DaMatta (1997a) sobre o mundo da casa e o mundo da rua.

A terceira fase se constituiu da análise conceitual e contextual dos dados coletados, à luz da fundamentação teórica, buscando identificar os significados da merenda escolar em suas representações e práticas, manifestos no contexto da escola tomada como espaço de estudo. Nessa fase, além das referências teóricas já mencionadas para organização e análise dos dados, teve particular importância a utilização do marco referencial metodológico "hermenêutica de profundidade”, desenvolvido por Thompson (1990). Trata-se de uma metodologia de interpretação das formas simbólicas concebidas como "construções significativas (ações, falas, textos etc.) que tipicamente representam algo, dizem alguma coisa sobre algo" ( $\mathrm{p}$. 375). A decisão de utilizar a interpretação das formas simbólicas (representações e práticas) relacionadas à merenda se deve ao objetivo pessoal de não restringir o estudo das representações sociais em foco à análise formal e descritiva.

A hermenêutica em profundidade favorece tanto a contextualização quanto a apreensão da constituição significativa da forma simbólica, permitindo inter- 
pretar as representações e as práticas relacionadas à merenda escolar, considerando o referencial histórico e social dos sujeitos que falaram na pesquisa, bem como os aspectos estruturais de suas falas.

\section{Para alguns, uma refeição ou a compensação por serviços prestados...}

No contexto social da comunidade onde se insere a escola onde se realizou a pesquisa, a merenda escolar extrapola tanto seu papel de complemento alimentar como os limites de sua cobertura determinados pela legislação que a regulamenta. Seja durante o período letivo, seja na colônia de férias, ela se manifesta como um instrumento que possibilita abrandar a fome de muitas pessoas: alunos, agregados da merenda, funcionários.

Além da alimentação precária, situação que afeta a maior parte dos moradores da comunidade, a falta de recursos humanos para a feitura/distribuição da merenda também favorece a existência de um grupo de pessoas que denominei agregados da merenda. ${ }^{9}$ Diante dessa realidade e sem perspectiva de contratação de pessoal para suprir carências nos serviços de merenda e de limpeza da escola, incentiva-se o trabalho dos agregados, utilizando a "moeda-alimento" para pagamento de uma mão de obra ociosa, faminta, que se submete a qualquer trabalho para conseguir pelo menos o alimento do dia e algumas sobras, até mesmo restos, para levar para casa.

Existem outros atores consumidores da merenda escolar: usufruem da merenda, diariamente, a maioria dos professores e funcionários administrativos, os seguranças e os prestadores de serviços comunitários, apenados da justiça; esporadicamente, os prestadores de serviço remunerado à escola (pintores, pedreiros), os agentes sanitários etc. Considerando o aspecto quantitativo, para esses atores e para os agregados a merenda deixa de ser uma ração, ${ }^{10}$ como é para os

\footnotetext{
${ }^{9}$ São todas mulheres e são denominadas pela gestão escolar como "amigas da escola”.

${ }^{10} \mathrm{O}$ termo ração não é concebido aqui como quantidade de alimento necessária para manter em boas condições de fun-
}

alunos, e adquire características de refeição. A sopa, a macarronada ou o baião de dois são servidos à vontade, ao contrário da "ração", medida de duas conchas, servida aos alunos. Nesse sentido, a merenda escolar adquire significados diferentes para os seus diferentes usuários: para os alunos, seus beneficiários por direito, uma ração; para os agregados e outros consumidores, uma refeição, um prato cheio ou servido à vontade, que pode amenizar a fome ou suprir a necessidade momentânea de alimentação.

Considerando a realidade do espaço escolar em foco, pode-se afirmar que a merenda escolar, agora descentralizada/escolarizada, continua marcada pelo clientelismo e pelo assistencialismo, características históricas do programa que eram atribuídas sobretudo à forma de gestão centralizada. Ademais, no cotidiano escolar, a merenda adquire uma dimensão que extrapola o limite das ações que beneficiam mais ou atendem melhor este ou aquele cliente. De maneira implícita e sutil, manifesta-se como uma atividade discriminatória que reforça a submissão do aluno, limita sua capacidade crítica e criativa e desqualifica sua cidadania. Além de ser servido em forma de ração, o aluno não é consultado sobre o que gostaria que fosse servido na merenda, submetendo-se ao consumo de alimentos que supostamente seriam de seu gosto na opinião dos gestores da escola e de funcionários da Secretaria da Educação do Ceará (SEDUC). O desejo e a vontade dos alunos em merendar coisas diferentes daquelas que consomem diariamente em casa não é considerada pelos gestores locais, que sempre elaboram o cardápio em função de suas representações sobre o aluno: criança carente, faminta, necessitada de um prato de comida e que come qualquer coisa. Então, os alimentos encorpados passam a predominar nos cardápios, sobretudo a sopa.

cionamento o organismo humano, mas no sentido de consumo alimentar limitado a uma quantidade insuficiente para o objetivo de garantir o funcionamento do organismo humano; insuficiente para ser considerado uma refeição e instrumento de recuperação de deficiências nutricionais, conforme afirmam os planejadores da política de merenda. 
Embora se trate de uma merenda da qual os alunos podem gostar (quando está bem feita, com aroma agradável e contendo suficiente carne ou frango), a sopa, em sua prática repetitiva, emerge como uma das principais reclamações dos alunos. A repetição e a exclusividade desse alimento - que é repetitivo não somente na escola, mas na rotina alimentar de muitos moradores do bairro -, elaborado com setenta litros de água e dez quilos de carne para cerca de quatrocentos alunos, davam-se também em função do irrisório valor per capita diário que o Fundo Nacional de Desenvolvimento da Educação (FNDE) repassava para as escolas. $\mathrm{O}$ valor de $\mathrm{R} \$ 0,13$ por aluno, ${ }^{11}$ uma quantia irrisória que, em conjunto com a quantidade de carne utilizada na confecção da sopa (dez quilos para mais de quatrocentos alunos), tem contribuído para a naturalização da merenda como uma esmola. Ademais, deve-se considerar que a previsão de recursos financeiros é feita com base em dados do censo escolar do ano anterior, sem levar em conta o crescente aumento anual do número de matrículas, que geralmente é atualizado sem retroativo a partir do segundo repasse de recursos, que acontece no mês de março.

Considerando que as práticas da merenda escolar desenvolvidas no interior da escola consistem da objetivação (Moscovici, 1978) das disposições representacionais de seus respectivos habitus (Bourdieu, 1994) que os administradores e docentes da escola têm sobre aluno e alimentação escolar, busco em seguida explicitar tais representações.

\section{Principal refeição do dia para crianças carentes e famintas e um "chama" para a escola}

As representações acerca da merenda escolar elaboradas por professores, gestores e merendeiras

${ }^{11}$ Esse valor per capita permaneceu de 1993 a 2004, quando foi elevado para $\mathrm{R} \$ 0,15$, chegando a $\mathrm{R} \$ 0,18$ em 2005. Tais reajustes foram provenientes da articulação do Programa Nacional de Alimentação Escolar (PNAE) ao Programa Fome Zero, do Governo Luiz Inácio Lula da Silva. têm como ponto de partida a internalização de uma concepção sobre os alunos que frequentam a escola: carentes, famintos, necessitados. Essa internalização, baseada na realidade concreta desses sujeitos, gera um habitus (Bourdieu, 1998) correspondente, orientando as representações sociais (Moscovici, 1978) desses atores sobre a merenda escolar que, por sua vez, direcionam as práticas relacionadas a essa atividade. Incorporado esse habitus, representam a merenda como a única alimentação diária garantida que a maioria dos alunos teria e motivo principal da frequência do aluno. Essa destacada importância atribuída à merenda direciona disposições práticas, tanto aquelas relacionadas ao comer na escola como as que dizem respeito à organização do trabalho pedagógico e à jornada escolar.

No discurso do grupo gestor da escola, especificamente a direção administrativa e a coordenação comunitária, a merenda escolar se define como uma atividade essencial para a escola, tanto quanto as atividades de ensino e aprendizagem. Ao priorizar na concepção de aluno a carência e a fome, a merenda deveria até evoluir de complemento alimentar para uma refeição, porque ela significaria para a maioria das crianças a refeição principal do dia e a única garantida, contribuindo para o aumento da importância da escola. Enfim, uma questão de sobrevivência. Ao associar merenda à sobrevivência, à carência, tomam como referência alguma situação prática que presenciaram ou da qual foram informados. Pressupondo que as famílias da maioria dos alunos sobrevivem de um salário mínimo ou menos, de renda incerta ou vivem o desemprego, comparam tal situação à vida das serventes da escola, que, apesar de receberem um salário mínimo, disputam as sobras de merenda para levar para casa.

Para os significados que os administradores entrevistados atribuem à merenda há uma imagem equivalente. Para a diretora administrativa, a merenda escolar, concebida como principal refeição do dia e motivação principal da frequência da criança carente e faminta à escola, objetiva-se (Moscovici, 1978) na imagem de um irmão de um aluno que teria comido 
uma cobra jararaca em estado de putrefação. ${ }^{12} \mathrm{~A}$ coordenadora comunitária, por sua vez, materializa o significado carência, sobrevivência, na figura do aluno insaciável, que repete duas, três vezes.

\section{Remédio contra todos os males: deficiência alimentar, absenteísmo e baixo rendimento em aprendizagem}

Para os professores, a merenda escolar é uma atividade essencial na escola, um importante complemento com função tríplice: ajudaria a recuperar a deficiência alimentar do aluno; determinaria a frequência do aluno; e contribuiria para melhor aprendizagem. A essência do discurso dos professores está marcada pela associação da merenda ao estado de carência e de fome do aluno.

Em face dessa concepção, a merenda emerge, na fala de todos os professores entrevistados, como um fator determinante tanto para a frequência como para o rendimento escolar do aluno.

É explícita a ideologia da carência, que concebe as camadas populares apenas como uma boca faminta e uma barriga vazia. Satisfeita a fome, a pessoa tornarse-ia feliz, porque sua vida giraria em torno da barriga. Isso contradiz as práticas alimentares das pessoas do sertão, local de origem da maioria das famílias do bairro. No sertão, predomina o gosto pela mesa farta, a alegria de ter comida e o status que essa posse dá ou a tristeza do não ter; enfim, "nosso jeito brasileiro de apreciar a mesa grande, farta, alegre e harmoniosa" (DaMatta, 1997b, p. 62).

Segundo os professores, quando há merenda, os alunos ficam felizes, alegres, não faltam e apresentam rendimento satisfatório em aprendizagem; na falta, o rendimento cai devido à falta de predisposição e vontade dos alunos, que não se concentram, ficam tristes, irritados, mais agitados e difíceis de controlar.

${ }^{12}$ Trata-se de rumor social sobre o qual não há evidências consistentes que indiquem que tenha acontecido.
Como consequência dessa representação de aluno carente, faminto, que iria à escola somente para comer, e das disposições práticas decorrentes, desencadeia-se a desqualificação da escola em seu papel de instituição destinada ao ensino e à aprendizagem, que é secundarizado pela alimentação. Por qual razão? Porque quando falta merenda os alunos, além de perder uma hora de aula, prejudicam-se também pela mudança na forma de condução das atividades pedagógicas, uma vez que são "deixados à vontade”, porque não teriam “condições de fazer nada”.

A merenda escolar como fator determinante da frequência e da aprendizagem do aluno objetiva-se na figura do aluno que não se alimentou antes de ir à escola. A consequência imediata dessa representação é a diminuição da carga horária diária em uma hora e a frequente supressão do recreio. Os alunos afirmam que as professoras os liberam mais cedo por vontade delas e que a insistência deles em sair mais cedo, quando não tem merenda, estaria mais relacionada ao que acontece dentro da sala de aula e à internalização da disposição que associa falta de merenda ao término da aula mais cedo, fato que acontece na escola há pelo menos uma década. Portanto, a ação de pedir para ir embora mais cedo quando não há merenda já constitui um habitus (Bourdieu, 1998) dos alunos.

Os dados levantados na escola não confirmaram a afirmação - já cristalizada entre a maioria dos profissionais da educação - de que o aluno só frequenta a escola pública por causa da merenda. O discurso dos alunos e das mães deixou bem claro que eles frequentam a escola pela escolarização em si e não para comer. Os dados da frequência diária mostraram que não há relação direta entre merenda escolar e ida do aluno à escola, pois a média de alunos em sala - duas classes de ciclo I, três de ciclo II, uma de aceleração e uma sala de alunos especiais - não se alterou de forma significativa na comparação entre o mês de maio (quando houve distribuição regular de merenda) e o mês de agosto (mês em que não houve).

Considerando representação social como "uma forma de conhecimento socialmente elaborada e partilhada tendo um objetivo prático e concorrendo à 
construção de uma realidade comum a um conjunto social" (Jodelet, 2001, p. 21) e a afirmação de Domingos Sobrinho (1997, p. 30) de que "assim como o habitus, ela [representação] é um guia para a ação, pois orienta as ações e relações sociais”, que ações são orientadas por tais representações sobre a merenda, no âmbito escolar?

\section{...para outros (os alunos), uma "ração" e reforço da submissão}

A prática mais imediata que decorre dessas representações sobre a merenda é a forma de elaboração dos cardápios, considerados como algo destinado à criança carente, faminta e necessitada de um prato de comida. Assim, predominam os alimentos salgados e encorpados, sobretudo a sopa, apesar de os gestores da escola saberem que os alunos preferem o iogurte, o leite com achocolatado, os sucos e o mingau acompanhados de pão, biscoitos ou sanduíche. Assim, a merenda adquire conotação de alimento destinado tão somente a matar a fome, e a sopa, por ter menor custo, torna-se o alimento mais servido, às vezes durante a semana inteira. Levando-se em conta que essas crianças geralmente têm a sopa como jantar, essa repetição se eleva a um índice bem maior. Contudo, em se tratando de merenda, o significado de matar a fome presente no discurso dos gestores é contraditório com a distribuição da merenda para os alunos, uma vez que é servida em forma de ração: duas conchas, no caso de sopa, baião de dois, macarronada, ou outro alimento salgado; uma caneca "pra cima do meio" quando é suco, iogurte ou leite achocolatado acompanhado de seis bolachas ou do tão apreciado e raríssimo pão recheado com carne moída ou ovo. Dessa forma, como "matar a fome" de alguém com um alimento tão racionado?

Está subjacente, nessa postura orientada pelo "matar a fome", a ideologia da carência, que sugere que pobre come tudo e de qualquer jeito e deve se satisfazer com o que lhe oferecem.

Reforçando essa representação e a ação consequente - que é o serviço repetitivo da sopa - está uma determinação objetiva: o valor per capita diário repassado pelo FNDE, na época R\$ 0,13 (treze centavos de real), determinado como o principal critério de definição sobre o que comprar: o produto de menor preço e não o de melhores características nutricionais e mais aceitáveis.

Outra manifestação concreta decorrente desse conhecimento prático da merenda relacionando-a a fome, à carência, acontece no plano do trabalho escolar, que se organiza em função da existência ou não da merenda. Quando há merenda, os alunos permanecem ali cerca de quatro horas; quando não há, o tempo de trabalho destinado às atividades curriculares é subtraído de uma hora e muitas vezes suprime-se o recreio para ganhar mais tempo e liberar os alunos mais cedo, uma hora e vinte antes do horário mínimo regulamentar, que é de quatro horas diárias. Os alunos ficam prejudicados com uma hora a menos de atividades escolares, diminuindo provavelmente o rendimento em aprendizagem, uma vez que permanecem os dois tempos de aula sem sair da sala. Ficam prejudicados ainda por não vivenciar o recreio, que se constitui, para a maioria dos alunos entrevistados, na atividade mais prazerosa da escola, porque é nessa hora que eles se sentem livres dos limites rigorosos que a sala de aula impõe.

Durante o tempo em que permaneci da escola, houve duas interrupções no fornecimento de merenda. Em agosto, a escola permaneceu por quatro semanas (20 dias letivos) sem merenda; a carga horária equivalente, que deveria ser de pelo menos 80 horas-aula, ficou reduzida a 60 horas. Isto é, o aluno perdeu 20 horas de atividades escolares por causa da falta de alimento. Segundo informação de uma funcionária da escola, essa prática de liberar os alunos uma hora mais cedo acontece na escola há pelo menos dez anos; ou seja, já é habitual. Diante disso e considerando que durante o mês de fevereiro, com 18 dias letivos, também faltou merenda, somam-se 18 horas-aula perdidas às 20 de agosto. Assim, foram 38 horas a menos durante o ano somente em função da falta de merenda, sem contar as supressões mensais do dia de pagamento dos professores, quando as aulas também terminam mais cedo, os atrasos costumeiros no início de cada jornada 
diária e outras interrupções esporádicas de distribuição da merenda decorrentes de falta água, de gás e falhas na sistemática de entrega dos gêneros alimentícios pelos fornecedores.

Esses fatos indicam que, no espaço escolar, a merenda emerge como um componente curricular significativo, que se manifesta pelo menos de duas maneiras. Uma delas se dá na relação já explicitada, em que a alimentação assume a forma de elemento de regulação da organização do trabalho escolar; a segunda acontece nos limites das disposições práticas diretamente relacionadas com o comer e suas respectivas implicações curriculares.

Por que afirmo que a merenda, nesse contexto, manifesta-se como uma atividade discriminatória que reforça o estado de submissão do aluno, limitando sua capacidade crítica e criativa e desqualificando sua cidadania? Porque não permite ao aluno interferir e/ou controlar a merenda, ao mesmo tempo em que concorre para que ele se sinta e se veja como pobre, carente de tudo, recebendo na escola pública um alimento tipo ração. O aluno não escolhe o cardápio, não se serve do alimento à vontade. Acrescente-se, como reforço, o conteúdo simbólico presente no ritual em si, que serve uma ração em local inadequado - nas salas de aula, pois as escolas públicas do Ceará não possuem refeitório -, bem como nos instrumentos usados no servir e no comer: bacias de plástico, pratos, copos e colheres também de plástico.

Todo esse processo tende a desencadear a interiorização, pelos alunos, de valores negativos e da ideologia da carência, gerando novas disposições, novos habitus e representações que tendem a naturalizar (Bourdieu, 1994) a situação de vida precária em que se encontra grande parte dos alunos da escola pública. Ademais, reforça a sensação de acesso desigual ao único bem público existente na comunidade (a escola) e à política social (merenda escolar) mais abrangente que aí se desenvolve; enfim, a sensação de injustiça social, que afeta as pessoas mais pobres da comunidade. Dessa forma, as práticas relacionadas ao comer na escola atuam como elementos curriculares que vão de encontro à possibilidade de a escola públi- ca contribuir no processo de emancipação (Oliveira, 1996) de seus alunos.

Acredito que a classificação da merenda escolar como a razão da existência da escola e do interesse dos alunos que a frequentam, presente no discurso dos diretores e professores, tende, por um lado, a "aumentar" a importância da escola; por outro, desqualificá-la como instituição escolar, ao secundarizar o seu papel de ensino e aprendizagem. Essa inversão de papel sugere uma tentativa de "salvação" da escola pública, via merenda, da crise por que passa atualmente. A merenda escolar tem de existir, necessitando se aperfeiçoar e superar os antigos vícios clientelistas e assistencialistas e os problemas atuais; no entanto, é inadmissível que ela adquira tamanha importância, chegando ao ponto de superar o papel da escola como instituição de saber. Percebo essa situação como uma forma de desqualificação do ensino público, porque afasta das camadas populares a possibilidade de busca de superação de seu estado de exclusão social - que acontece também através da escola - ao mesmo tempo em que as culpa pelo fracasso do aluno.

É injusta essa inversão do papel da escola pública justamente numa comunidade onde o único serviço público de acesso garantido é o ensino fundamental. A escola deve fornecer merenda como um complemento alimentar equivalente às necessidades calórico-proteicas dos alunos durante as quatro horas de atividades curriculares. Apenas isso. Não lhe cabe, portanto, assumir funções paliativas de assistência social que só ajudam a manter o estado de pobreza e miséria dominante. Essa inversão de papel, que omite as causas estruturais dessa crise e a parcela de responsabilidade do Ministério da Educação, das secretarias estaduais e municipais de educação, da escola e dos professores na constituição de tal problemática, neutraliza tanto a possibilidade de tomada de posição das pessoas envolvidas com a educação escolar pública - pais, alunos, professores, administradores - como a crítica decorrente, que constitui o momento inicial e indispensável ao desenvolvimento de um processo efetivo de pensar e reconstruir essa escola, direcionando-a à criação de possibilidades que concorram para a 
superação do estado de exclusão em que se encontra a maioria da população.

\section{A falta da merenda faz aluno emagrecer e desmaiar}

As representações da merenda elaboradas pelas merendeiras também partem da concepção de aluno carente. $\mathrm{O}$ comer significaria uma atividade muito importante para a ida do aluno à escola, estando, porém, em igualdade de importância com o estudo, com a vontade de aprender. Ou seja, os alunos, por serem carentes, compareceriam à escola motivados tanto pelo estudo quanto pela busca de alimento. Apesar de atribuir à merenda um significado semelhante ao emitido por professores/diretores, as merendeiras não veem essa atividade como fator exclusivo de determinação da frequência do aluno, mas como elemento de destacada importância. Isso se deve, sobretudo, ao fato de todas as merendeiras morarem na comunidade (uma das quais tem filhos estudando na escola) e conceberem a educação escolar como um caminho para conseguir um bom emprego e, consequentemente, melhorar suas condições de vida.

Quando admitem existir alguns alunos que frequentariam a escola mais para comer, a merenda aparece como a única alimentação do dia para eles, fato que estaria diretamente relacionado à falta de emprego, uma vez que, se os pais dessas crianças tivessem empregos dignos e razoavelmente remunerados, não haveria nem a necessidade da comida na escola.

Representar a merenda vinculado-a à carência dos alunos e a suas precárias condições de vida materializa-se, para as merendeiras, na imagem do aluno que teria desmaiado de fome e naquele que teria voltado das férias mais magro. Elas confirmam ainda o desejo do aluno pelo alimento diferente e a não-consideração dos desejos dos alunos na elaboração dos cardápios e percebem descompasso entre a proposta oficial, apresentada de forma espetacular na propaganda da merenda na televisão, e o monótono e repetitivo cardápio que se põe em prática nas escolas.

\section{A merenda é só sopa: “... todo dia é sopa, sopa, sopa e sopa"}

Para os alunos, as representações acerca da merenda são elaboradas a partir de um enfoque diferente: à semelhança do recreio, a merenda é algo de que eles podem gostar na escola. Um gostar dependente do cardápio, do tipo de alimento servido, da forma, do cheiro, do gosto e da higiene. As referências à merenda geralmente surgem quando eles emitem opinião sobre as coisas da escola das quais não gostam, ressaltando o predomínio da sopa, o descuido na feitura de alguns alimentos e a ausência daquilo que eles gostariam de comer. Assim, representam a merenda como o alimento que não corresponde aos gostos deles. Essa não-correspondência da merenda aos gostos e anseios não se restringe ao alimento em si, mas se aplica também à prática do servir/consumir com instrumentos (bacias, pratos, copos e colheres) que às vezes causam repugnância.

As comidas preferidas pelos alunos são exatamente aquelas que raramente são ofertadas: iogurte com biscoito, suco com sanduíche de carne, macarronada, leite achocolatado com biscoito ou pão. A raridade desses alimentos - à exceção do iogurte, que é mais caro - não se deve somente à opção forçada pelo produto mais barato decorrente do baixo valor per capita repassado pelo FNDE à escola, mas do predomínio da opinião dos administradores na elaboração do cardápio tendo por base a representação de aluno carente, faminto e necessitado de um prato de sopa. Não importa se a sopa se repete a ponto de atingir nível elevado de rejeição nem a privação do prazer e do deleite que o aluno sentiria ao ingerir sua comida preferida, mas a oferta de alimento encorpado com a finalidade de encher barriga. Dessa forma, seria predominantemente alimento e raramente comida, considerando as concepções de DaMatta (1997b). Até mesmo a finalidade de encher a barriga não é atingida, uma vez que a merenda é servida como ração, apenas duas conchas de sopa.

Assim, a representação de merenda para o aluno emerge, por um lado, como um alimento saturado pela oferta, que geralmente não corresponde à sua vonta- 
de e sem relação com sua ida à escola; por outro, a merenda desejada se orienta para comidas diferentes daquelas que ele come em casa. Não é associada à frequência, pois ele sabe com muita clareza o porquê de estar frequentando a escola: para ter um trabalho bom: ser veterinário, pedreiro etc.; ir à escola significa, portanto, possibilidade de conseguir um emprego bom, suficiente para se manter e ajudar a família.

Assim, as representações que os alunos elaboram sobre merenda diferem significativamente das expressas pelos gestores, professores e pelo grupo de merendeiras. Isso reflete as assimetrias existentes entre os dois grupos (alunos e professores/gestores), que ocupam posições diferentes tanto no meio social quanto no interior da escola. Assimetrias que, no espaço escolar, revestem-se de poder para administradores/ professores e geram ausência de participação dos alunos e seus pais nas decisões sobre assuntos da escola. Ademais, as merendeiras, apesar de pertencerem ao meio social dos alunos, elaboram representações sobre a merenda que se aproximam mais daquelas dos professores/gestores, porque já vivenciam há muito tempo (no mínimo quinze anos) o cotidiano escolar, impregnando-se das representações que ali circulam e que naturalizam a afirmação de que o aluno vai à escola principalmente por causa da alimentação.

\section{A merenda é importante, porém grosseira, fraca; pouca, sem sustância e sem relação com a frequência do aluno}

As representações sociais sobre a merenda escolar elaboradas por mães de alunos oscilam entre o enfoque nos aspectos negativos e positivos e a ênfase na forma de como deveria ser. Este último decorre do predomínio dos aspectos negativos e indica o que gostariam que os filhos comessem na escola, sobretudo comidas diferentes daquelas "habitualmente" consumidas em casa e daquelas servidas na escola.

Os aspectos negativos da merenda estão relacionados à sua composição, considerada fraca, sem sustância e servida em pouca quantidade. Representam-na como repetitiva, com gosto inadequado e descuidada durante a feitura e a distribuição. Ademais, consumir merendas como baião de dois ou sopa às $9 \mathrm{~h}$ ou às $15 \mathrm{~h}$ afeta o ritmo alimentar da criança em casa.

Em poucos momentos a sopa aparece como alimento preferido dos filhos, sendo logo substituída por outro mais preferido. Nota-se que o gosto atribuído pela mãe à sopa ou ao baião de dois servidos na escola está mais relacionado à satisfação biológica, pois quando falam que a sopa estava boa fazem no sentido de ocorrência esporádica, indicando que usualmente ela não é gostosa. A ênfase no destaque positivo da merenda está em motivo de ordem prática: a não-procura de alimento pelos filhos quando chegam a suas casas. O prazer mesmo do gosto, a satisfação completa estaria em outros alimentos que, apesar de preferidos, têm frequência de distribuição mínima ou nula na escola.

Está ausente no discurso das mães a afirmação presente na fala dos professores e gestores, de que o aluno vai à escola por causa da comida. Quando essas mães são instigadas sobre o assunto, elas afirmam que muitos alunos vão pelo atrativo da merenda porque é mais fácil estudar quando há merenda, mais difícil quando não há, e é ruim ficar o longo período da aula sem se alimentar. Quando questionadas sobre a relação direta entre frequência do aluno e merenda, como afirmam os professores, apenas uma das mães disse ter notícia de aluno que iria só para comer; seria uma criança que mora na favela, nas ruas de baixo ou numa rua mais embaixo daquela em que ela mora.

Por que a merenda não possui relação com a frequência dos alunos no discurso dos pais? Assim como na fala dos alunos, as mães afirmam procurar a escola em busca de educação para seus filhos, o que resultaria na melhora das condições materiais de vida via trabalho. Ademais, outros motivos movem essa procura, como a preparação para a convivência social, a proximidade de casa, o que dá tranquilidade, porque o filho não se arrisca bairro afora, expondo-se à violência e às drogas. E a merenda? É muito importante e motiva o aluno, como se afirmou; mas, em se tratando especificamente da relação da família com a escola, da procura pela escola, a merenda passa ao largo, porém é “uma coisa que podia acabar e não podia acabar”. 
Enfim, a dimensão do deveria ser se explicita nas representações sobre a merenda: alimentação adequada, forte (com sustância), gostosa, temperada, variada e coisa diferente. Todas essas características procuram ultrapassar os aspectos dessa atividade que incomodam alunos e seus pais. Essas pessoas vivem uma realidade marcada pela carência alimentar. Suas dietas são monótonas e restritas ao feijão com arroz diário, acrescido alguma vez de uma mistura (ovo, presunto, mortadela, sardinha etc.). Se o frango é raro, uma comida dos dias de domingo, a carne não faz parte dessa dieta. Complementando essa rotina alimentar, entram o café e o pão. Geralmente não consomem leite, nem mesmo as crianças.

Tendo como referência essa vivência, o que esses sujeitos esperam encontrar na merenda escolar? O diferente, o que não comem em casa: o leite, o suco, o sanduíche, o biscoito, a carne, o frango. A expectativa de uma alimentação melhor acompanha a expectativa de um lugar melhor (a escola) do que suas casas e que pode fazê-los melhorar de vida. Além disso, comida envolve um conjunto de características que extrapolam o aspecto físico, biológico: ela implica prazer, gosto, rituais de recusa ou rejeição, de aproximação das pessoas, de distinção social. Afinal, ninguém sai de casa para comer fora aquilo que come no seu dia a dia. Mesmo tendo uma dieta precária, os alunos e suas famílias têm gostos, sensibilidade no comer, sonham com algumas comidas e esperam encontrá-las na escola.

As representações das mães sobre a merenda escolar coincidem, então, com aquelas elaboradas por seus filhos/alunos: não correspondem ao que gostariam de comer, é alimento grosseiro, sem gosto e sem cheiro, saturado pela repetição. O comer na escola é mais uma das práticas desenvolvidas na escola - não determinante da frequência, mas que contribui para o processo de aprendizagem do aluno.

\section{Palavras finais}

Por fim, este estudo permite afirmar que as representações sociais acerca da merenda escolar elaboradas pelos profissionais da escola tendo como predisposição a concepção de aluno carente, necessitado de um prato de comida e que come qualquer coisa, gera um habitus correspondente que tende a orientar as disposições práticas relacionadas ao comer na escola (servindo repetidamente alimentos encorpados), à organização do trabalho pedagógico (elaborado em função da merenda) e à jornada escolar (reduzida em períodos de falta de alimentação). Ademais, as práticas relacionadas à merenda escolar que, no caso estudado, orientam-se somente pelas representações dos profissionais da escola atuam como elemento curricular de reforço à submissão dos alunos e tendem a naturalizar a situação de exclusão em que a maioria deles se encontra.

\section{Referências bibliográficas}

ANDRÉ, Marli Eliza Dalmazo Afonso de. Metodologia da pesquisa educacional. São Paulo: Cortez, 1989.

APPLE, Michael W. Educação e poder. Trad. Maria Cristina Monteiro. Porto Alegre: Artes Médicas, 1989.

Conhecimento oficial. A educação democrática numa era conservadora. 2. ed. Trad. Maria Isabel Edelweiss Bujes. Petrópolis: Vozes, 1999.

. Repensando ideologia e currículo. In: MOREIRA, Antônio Flávio Barbosa e SILVA, Tomaz Tadeu da (Org.). Currículo, cultura e sociedade. 2. ed. São Paulo: Cortez, 1995.

ARON, Raymond. Émile Durkheim. In: ARON, Raymond. As etapas do pensamento sociológico. 4. ed. Trad. Sérgio Beth. São Paulo: Martins Fontes, 1993.

BOURDIEU, Pierre. O poder simbólico. 2. ed. Trad. Fernando Tomaz. Rio de Janeiro: Bertrand Brasil, 1998.

. Trabalhos e projetos. In: ORTIZ, Renato (Org.).

Pierre Bourdieu. 2. ed. São Paulo: Ática, 1994. (Coleção Grandes Cientistas Sociais, 39.)

CARVALHO, Maria do Carmo Brant de; PAULO NETTO, José. Cotidiano: conhecimento e crítica. 4. ed. São Paulo: Cortez, 1996. DaMATTA, Roberto. A casa \& a rua: espaço, cidadania, mulher e morte no Brasil. 5. ed. Rio de Janeiro: Rocco, 1997a.

. O que faz o brasil, Brasil? 8. ed. Rio de Janeiro: Rocco, 1997b.

DOMINGOS SOBRINHO, Moisés. Classe média assalariada e representações sociais da educação: algumas questões de ordem teórico-metodológicas. In: MADEIRA, Margot Campos (Org.). 
Representações sociais e educação: algumas reflexões. Natal: EDUFRN, 1997.

ESCOLANO, Agustín. Arquitetura como programa. Espaço-escola e currículo. In: FRAGO, Antonio Viñao; ESCOLANO, Agustín. Currículo, espaço e subjetividade - a arquitetura como programa. Trad. Alfredo Veiga-Neto. Rio de Janeiro: DP\&A, 1998.

HELLER, Agnes. O cotidiano e a história. 4. ed. Trad. Carlos Nelson Coutinho e Leandro Konder. Rio de Janeiro: Paz e Terra, 1992. JODELET, Denise. Representações sociais: um domínio em expansão. $I n$ : (Org.). As representações sociais. Rio de Janeiro: Ed. UERJ, 2001. p. 17-44.

MOREIRA, Antônio Flávio; SILVA, Tomaz Tadeu da. Sociologia e teoria crítica do currículo: uma introdução. In: MOREIRA, Antônio Flávio; SILVA, Tomaz Tadeu da (Org.). Currículo, cultura e sociedade. 2. ed. São Paulo: Cortez, 1995.

MOSCOVICI, Serge. A representação social da psicanálise. Trad. Álvaro Cabral. Rio de Janeiro: Zahar, 1978.

OLIVEIRA, Manfredo Araújo de. A teoria da educação no conflito das racionalidades. $I n$ : . Tópicos de dialética. Porto Alegre:

EDIPUC-RS, 1996.

SAMPAIO, José Levi Furtado. A fome e as duas faces do estado do Ceará. 1999. Tese (Doutorado em Geografia Humana) - Faculdade de Filosofia, Letras e Ciências Humanas, Universidade de São Paulo, São Paulo, 1999. THOMPSON, John B. Ideologia e cultura moderna: teoria social crítica na era dos meios de comunicação de massa. 2. ed. Trad. Grupo de Estudos sobre Ideologia, Comunicação e Representações Sociais da Pós-Graduação do Instituto de Psicologia da PUC-RS. Petrópolis: Vozes, 1990.

ZALUAR, Alba. A máquina e a revolta: as organizações populares e o significado da pobreza. São Paulo: Brasiliense, 1985.

JOSÉ ARIMATEA BARROS BEZERRA, doutor em educação pela Universidade Federal do Ceará (UFC), é professor da área de política educacional no curso de pedagogia e de antropologia da alimentação no curso de educação física da mesma universidade, na qual atua também no Programa de Pós-Graduação em Educação. Publicações recentes: Eugenia, nacionalismo e higienismo: as bases do discurso sobre a alimentação da criança na escola (Fortaleza: Imprece, 2004); Do Programa Nacional de Merenda Escolar (1954) ao Programa Fome Zero (2003): rastros do itinerário da política de alimentação escolar no Brasil (Fortaleza: Ed. UFC, 2005); Regionalização de cardápios, fortalecimento das economias locais e participação da população na gestão descentralizada da merenda escolar (Fortaleza: Ed. UFC, 2007). Pesquisa em andamento: “O processo de gênese do saber em alimentação no Ceará (1940-1973)”. E-mail: ja.bezerra@uol.com.br Recebido em dezembro de 2007 Aprovado em setembro de 2008 